\title{
International Union Against Cancer
}

National Cancer Institute

\section{Source}

National Cancer Institute. International Union Against Cancer. NCI Thesaurus. Code C39434.

The International Union Against Cancer (UICC) is the only global cancer organisation with members and activities covering all aspects of cancer control. Founded in 1933, UICC is an independent, international, non-governmental association of 291 member cancer fighting organizations in 87 countries. Located in Geneva, Switzerland. 